\title{
К ВОПРОСУ ТЕРМОКАТАЛИТИЧЕСКОГО ДЕАЛКИЛИРОВАНИЯ СЛАНЦЕВЫХ 5-АЛКИЛРЕЗОРЦИНОВ
}

При деалкилировании сланцевых длинноцепочечных 5-алкилрезорцинов (5-AР) с катализаторами различных типов выяснилось, что самые лучшие результаты получаются на активных углях, в частности, на углях марки АГ-5 [ $\left.{ }^{1}\right]$. В $\left[^{2-4}\right]$ было установлено, что оптимальные условия проведения деалкилирования, с выходом 46,5\% водорастворимых 5 -АР, - остаточное давление $13,3 \kappa \Pi a$, температура $572{ }^{\circ} \mathrm{C}$, время контакта около 1,5 с и мольное соотношение водорода и сырья $2: 1$. Было показано и то, что основной фактор, влияющий на выход целевых продуктов, - температура. Другие факторы влияют значительно слабее, особенно мольное соотношение водорода и сырья.

Деалкилирование 5-AР проходит труднее, чем деалкилирование одноатомных алкилфенолов, поскольку 5-АР, имеющие две гидроксильные группы в мета-положении, обладают повышенной реакционной способностью к реакции конденсации, что уменышает выход целевых соединений. Известно также, что в случае 2-алкил- и 4-алкилрезорцинов реакция протекает с бо́лышим выходом целевых продуктов и побочные реакции значительной роли не играют [5]. Такие катализаторы, как алюмосиликаты, уголь, активированный карбонатом натрия или $\mathrm{H}_{3} \mathrm{BO}_{3}$, или $\mathrm{Ni}-\mathrm{Cr}$, способствуют деструктированию материала в большей мере, чем необработанный уголь. Так, на угле, металлизированном никелем и хромом, алкилрезорцины практически полностью разрушаются при $500^{\circ}\left[^{1}\right]$. С другой стороны, известно, что одноатомные фенолы в этих условиях могут быть деалкилированы с хорошим выходом [6]. Катализаторы полярного типа, по-видимому, способствуют разложению молекулы в полярной части, и чем полярнее соединения, тем сильнее выражено такое направление реакции.

Имеющиеся данные о термическом разложении алкилрезорцинов [5], одноатомных алкилфенолов [7,8] и алкилбензолов $[9,10]$ свидетельствуют о том, что образованию низших гомологов способствуют первичные радикалы, возникающие при разрыве алкильной цепи и соединяющиеся далее с атомом водорода. В этих работах также установлено, что при деалкилировании длинноцепочечных алкилфенолов наименее прочны в боковой цепи $\beta$ - и $\gamma$-связи. Селективность разрыва этих связей зависит от положения алкильной группы у ароматического ядра. В мета-положении расщепление менее селективно, чем в орто- и nара-положениях. Поскольку не имеется данных о механизме образования низших гомологов 5-АР при гетерогенном деалкилировании их длинноцепочечных представителей, то цель данной работы - дать некоторое представление об этом вопросе.

Эксперименты проводили в заранее заданных оптимальных условиях, приведенных выше, - в токе газа-разбавителя (водород, азот или водяной пар), уносящего пары фенолов из испарителя в реактор, наполненный стационарным слоем катализатора в объеме 14 мл. Количество иопарившихся фенолов, проходящих через реактор, составило 
Характеристика 5-АР в исходном сырье

и тяжелой части катализата, мас.\%

\begin{tabular}{c|c|r|r|r}
\hline \multirow{2}{*}{$\begin{array}{c}\text { Число углерод- } \\
\text { ных атомов в } \\
\text { боковой цепи }\end{array}$} & \multirow{2}{*}{ Сырье } & \multicolumn{3}{|c}{ Катализат } \\
\cline { 3 - 5 } & & водород & азот & водяной пар \\
\hline 0 & 0 & 1,85 & 2,35 & 2,17 \\
1 & 0,64 & 1,28 & 13,08 & 13,34 \\
2 & 0,78 & 9,89 & 10,08 & 9,96 \\
3 & 0,57 & 1,35 & 1,30 & 1,27 \\
4 & 2,80 & 2,92 & 3,20 & 3,02 \\
5 & 5,80 & 1,19 & 1,34 & 1,25 \\
6 & 6,43 & 0 & 0,31 & 0,23 \\
7 & 7,30 & 0,22 & 0,39 & 0,28 \\
8 & 6,74 & & & \\
9 & 3,38 & & & \\
10 & 2,04 & & & \\
11 & 0,67 & & & \\
12 & 0,61 & & & \\
13 & 0,10 & & & \\
14 & 0,03 & & & \\
15 & 0,01 & & 14,5 & 14,7 \\
Молекулярная & 202 & 162 & & \\
масса & & & & \\
Содержание & 14,23 & 14,8 & 163 & \\
ОН-групп & 14,23 & & & \\
\end{tabular}

Примечани е: Содержание 5-АР определено при помощи внутреннего стандарта, которым служнл 3,4-ксиленол. Остальные данные, приведенные в табл. 3 и 4, получены с применением метода внутренней нормализацин.

Таблица 2

Выход отдельных частей катализата при деалкилировании концентрата 5-АР в различных средах, мас.\%

\begin{tabular}{|c|c|c|c|}
\hline Фракция катализата & Водород & Азот & Водяной пар \\
\hline Тяжелая часть, конденсированная при & 47,9 & 47,5 & 48,0 \\
\hline $\begin{array}{l}\text { Легкая часть, конденсированная при } \\
\text { температуре жидкого азота, в том числе: } \\
\text { a) при } 18-20^{\circ} \text { (жидкость) } \\
\text { б) при } 18-20^{\circ} \text { (газ) } \\
\text { в) вода } \\
\text { Часть, оставшаяся на катализаторе } \\
\text { Потери (неконденснрующаяся часть) }\end{array}$ & $\begin{array}{r}29,1 \\
13,5 \\
10,3 \\
5,3 \\
18,4 \\
4,6\end{array}$ & $\begin{array}{r}29,1 \\
15,1 \\
8,5 \\
5,6 \\
17,4 \\
5,5\end{array}$ & $\begin{array}{r}29,0 \\
13,8 \\
9,8 \\
5,4 \\
17,6 \\
5,4\end{array}$ \\
\hline
\end{tabular}

$90 \%$ исходного сырья. В каждом опыте на 1,0 г катализатора расходовали 1,1 г сырья. Высококипящая часть катализата улавливалась в приемнике при $18-20^{\circ}$, а легкая - и газообразная - при температуре жидкого азота. Фенольным сырьем служил концентрат 5-АР (табл. 1), выделенный из фракции 230-360 сланцевой смолы по описанному ранее методу [1']. Использованные нами фенолы, кроме 5-AР, других соединений с длинными цепями алифатического строения не содержали.

Количественный анализ проводили газохроматографически. Сырье и высококипяшую часть катализата анализировали на колонках ( $\varnothing 3$ мм и $l=3,0 \mathrm{M})$, заполненных сорбентом $15 \%$ апьезона $L$ на хроматоне $\mathrm{N}$ AW DMCS [3], легкую часть - на капиллярной колонке $(\varnothing 0,25$ мм и $l=150 \mathrm{M})$ с применением полифенилового эфира; газовые продук- 

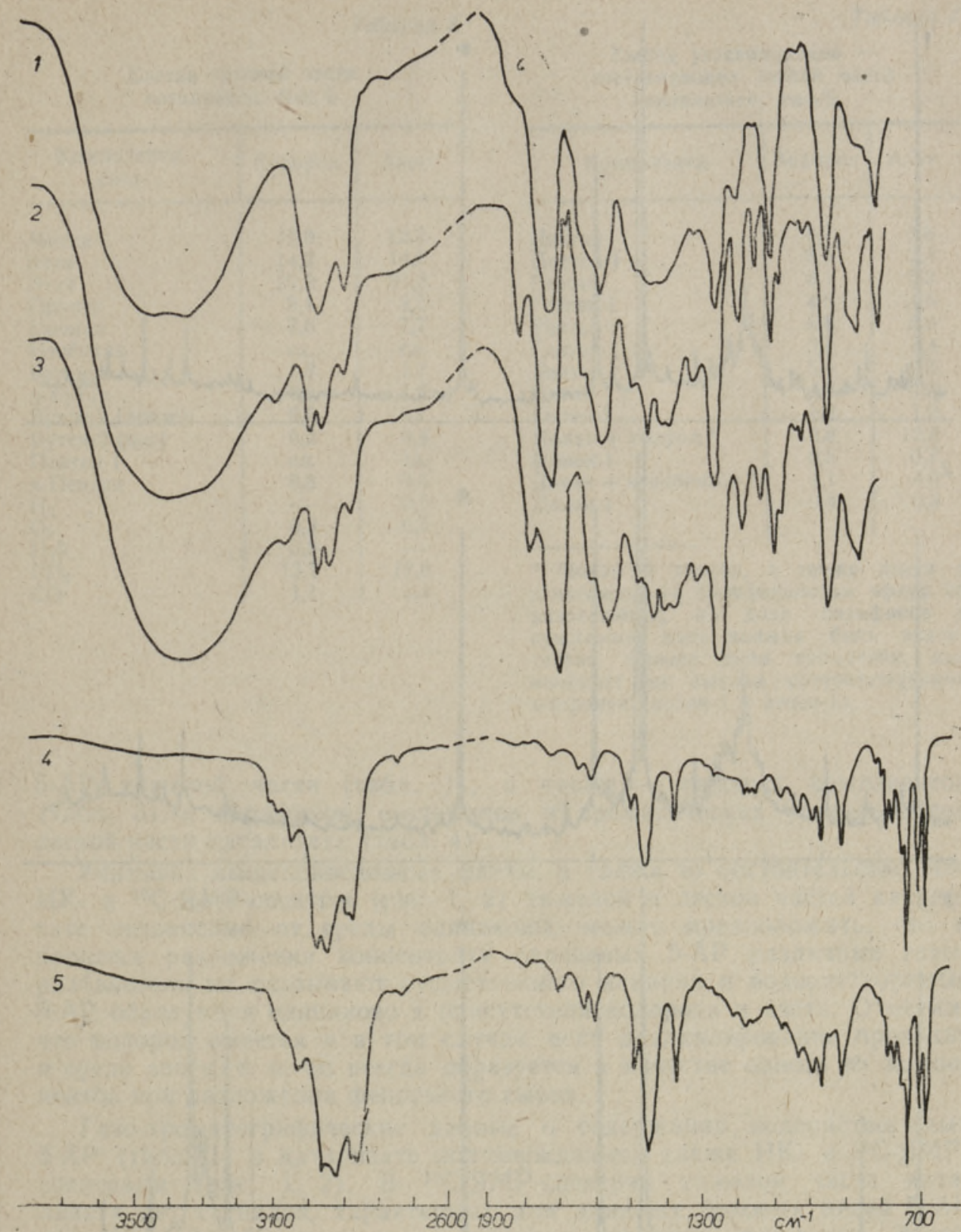

Рнс. 1. ИК-спектры концентрата 5-АР и продуктов, полученных из него при термокаталитическом деалкилировании. 1 - концентрат 5-АР; 2, 3 - тяжелая часть катализата в среде азота и водорода; 4,5 - легкая часть катализата, полученная в среде азота и водорода.

ты - на молекулярном сите $\mathrm{NaX}$ и гексадекане по ГОСТу 14920-79. ${ }^{13} \mathrm{C}$-ЯМР-спектры снимали на приборе FT-80A «Varian» при частоте $20 M Г ц$. Растворителем служил хлороформ, принятый в качестве стандарта при расчете химических сдвигов линий спектров относительно тетраметилсилана. ИК-спектры проб снимали на приборе UR-20 в тонком слое, материал кюветы - хлористый натрий.

Как видно из табл. 2, при разложении в разных средах выходы 

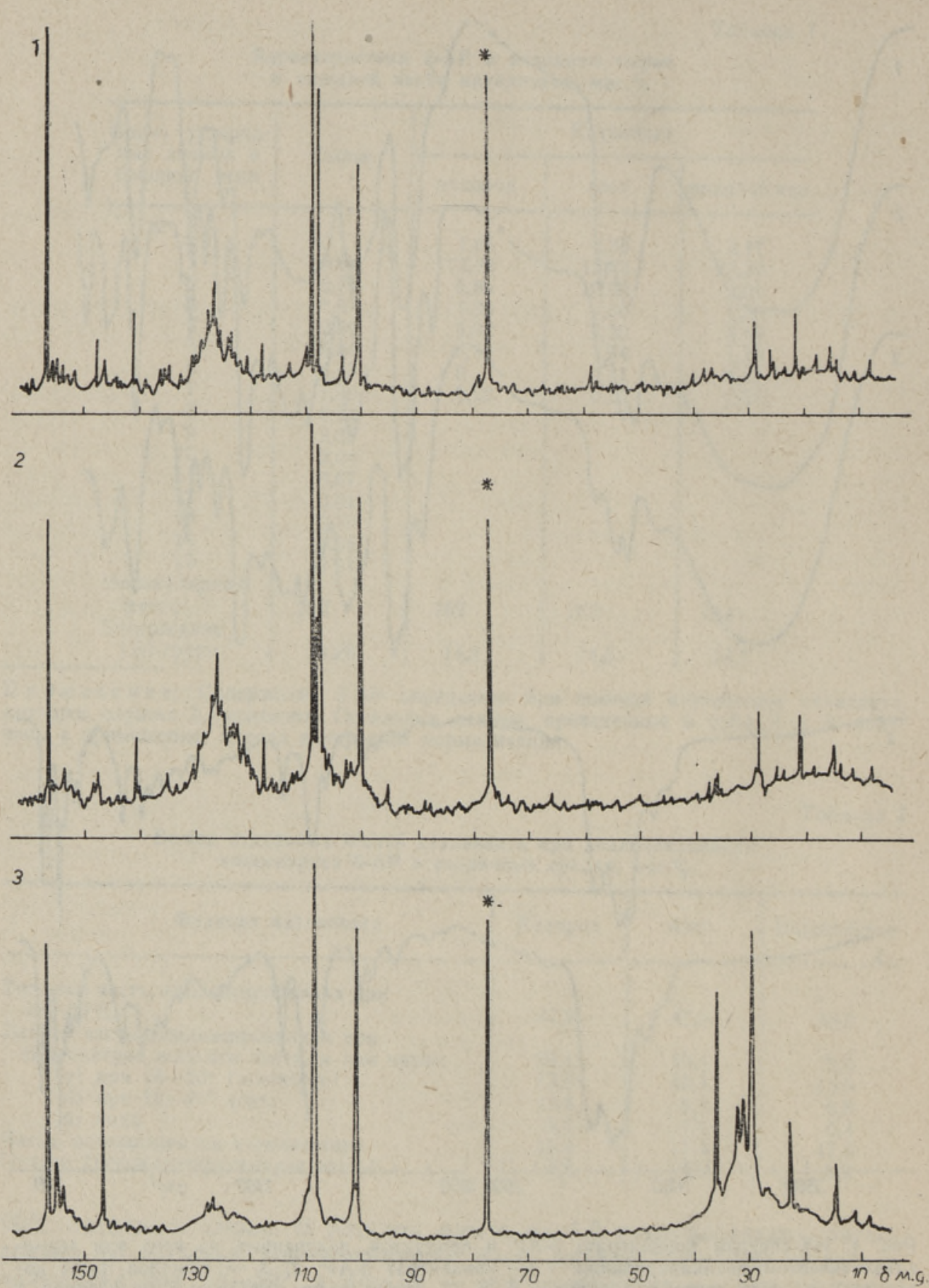

Рис. 2. ${ }^{13}$ С-ЯМР-спектры концентрата 5-АР и продуктов, полученных из него при термокаталитическом деалкилировании. 1,2 - тяжелая часть катализата в среде азота и водорода; 3 - концентрат 5-АР.

отдельных частей катализата существенной разницы не имеют. Не зависят от среды также выход воды и количество частей, связанных катализатором*. Такая же закономерность наблюдается и в составе

* Части, связанные катализатором, не растворились ни в смеси метанола и бензола, ни в водно-бутанольном растворе $10 \%$-ного $\mathrm{NaOH}$ при температуре $70-80^{\circ}$. 
Состав газовой части катализата, мас.\%

\begin{tabular}{l|r|r}
\hline \multicolumn{1}{c|}{$\begin{array}{c}\text { Компоненты } \\
\text { газа }\end{array}$} & Водород & Азот \\
\hline Метан & 19,0 & 12,3 \\
Этен & 14,2 & 14,7 \\
Этан & 29,2 & 31,3 \\
Пропен & 9,4 & 9,3 \\
Пропан & 7,6 & 7,7 \\
Изобутан & сл. & сл. \\
Бутен-1 & 1,8 & 1,7 \\
н-Бутан & 1,9 & 1,8 \\
Бутен-2 (транс) & 0,6 & 0,7 \\
Бутен-2 (цис) & 0,2 & 0,4 \\
Пентен-1 & сл. & сл. \\
н-Пентан & 0,8 & 0,5 \\
$\mathrm{H}_{2}$ & - & 0,1 \\
$\mathrm{O}_{2}$ & 0,3 & 0,5 \\
$\mathrm{H}_{2} \mathrm{~S}$ & 0,8 & - \\
$\mathrm{CO}_{2}$ & 13,1 & 17,6 \\
$\mathrm{CO}^{2}$ & 1,1 & 1,4 \\
& &
\end{tabular}

Выход углеводородов составляющих легкой части катализата, мас.\%

\begin{tabular}{l|r|r}
\hline \multicolumn{1}{c|}{ Компоненты } & Водород & Азот \\
\hline & & \\
\hline Пентан & 6,7 & 3,6 \\
Пентен-1 & 3,5 & 2,1 \\
Гексан & 8,1 & 6,9 \\
Гексен-1 & 4,5 & 4,6 \\
Гептан & 5,8 & 5,9 \\
Гептен-1 & 3,0 & 3,4 \\
Бензол & 5,4 & 5,5 \\
Октан & 4,3 & 4,4 \\
Октен-1 & 1,3 & 1,6 \\
Нонан + толуол * & 12,8 & 12,4 \\
Нонен-1 & 0,5 & 0,7 \\
Декан + этилбензол * & 4,1 & 4,0 \\
Децен-1 & 0,4 & 0,6 \\
& &
\end{tabular}

* Нонан и толуол, а также декан и этилбензол на полифениловом эфире не разделяются, но доля парафинов в суммарном пике должна быть значигельно меньше доли ароматики, как вытекает ия выхода соответствующих олефинов (нонен-1 и децен-1).

5-АР тяжелой части (табл. 1), а также - газовых компонентов (табл. 3) и парафинов, $\alpha$-олефинов и ароматических углеводородов легкой части катализата (табл. 4).

Учитывая вышеприведенные факты, а также то обстоятельство, что ИК- и ${ }^{13}$ С-ЯМР-спектры (рис. 1,2 ) тяжелой и легкой частей катализата независимо от среды одинаковы, можно предположить, что в процессе разложения концентрата сланцевых 5-АР различные газыразбавители не оказывают существенного влияния и водорастворимые 5-АР образуются одинаково в присутствии водорода и азота. Отметим, что водород имеется и в том случае, если деалкилирование проходит в среде азота, т. к. он всегда образуется в качестве одного из компонентов при разложении фенольного сырья.

Газо-хроматографические данные о содержании водорастворимых 5-АР (табл. 1) в катализате подтверждаются также ИК- и ${ }^{13} \mathrm{C}$-ЯМРспектрами (рис. 1,2). В ${ }^{13}$ С-ЯМР-спектрах тяжелой части катализата нет сигналов, характерных для длинных боковых цепей 5-АР $(15-30$ м. д.). Имеются только сигналы коротких алкилыных цепей. В ИК-спектрах тяжелой части катализата увеличивается содержание метильных групп (2965 $\left.\mathrm{cm}^{-1}\right)$ и, наоборот, уменьшается число метиленовых групп $\left(2865,2930 \mathrm{~cm}^{-1}\right)$. Это явление овидетельствует об укорочении боковой цепи.

Образование первых членов 5-АР при деалкилировании их высших гомологов подтверждается также появлением в продуктах разложения парафинов и $\boldsymbol{\alpha}$-олефинов (табл. 3,4$)$. В ИК-спектрах легких частей катализата возникают характерные им линии $(1455,1630,2865,2875$, 2930 и $2965\left(\mu^{-1}\right)$. При деалкилировании на активном угле разрыв связи в алкильной цепи происходит прежде всего в $\beta$-положении и только потом в $\gamma$ - и $\alpha$-положениях, доказательством чего служит выход 5-метилрезорцина (5-MP), 5-этилрезорцина (5-ЭР) и резорцина (табл. 1), а также парафинов и $\alpha$-олефинов, образующихся в резуль- 


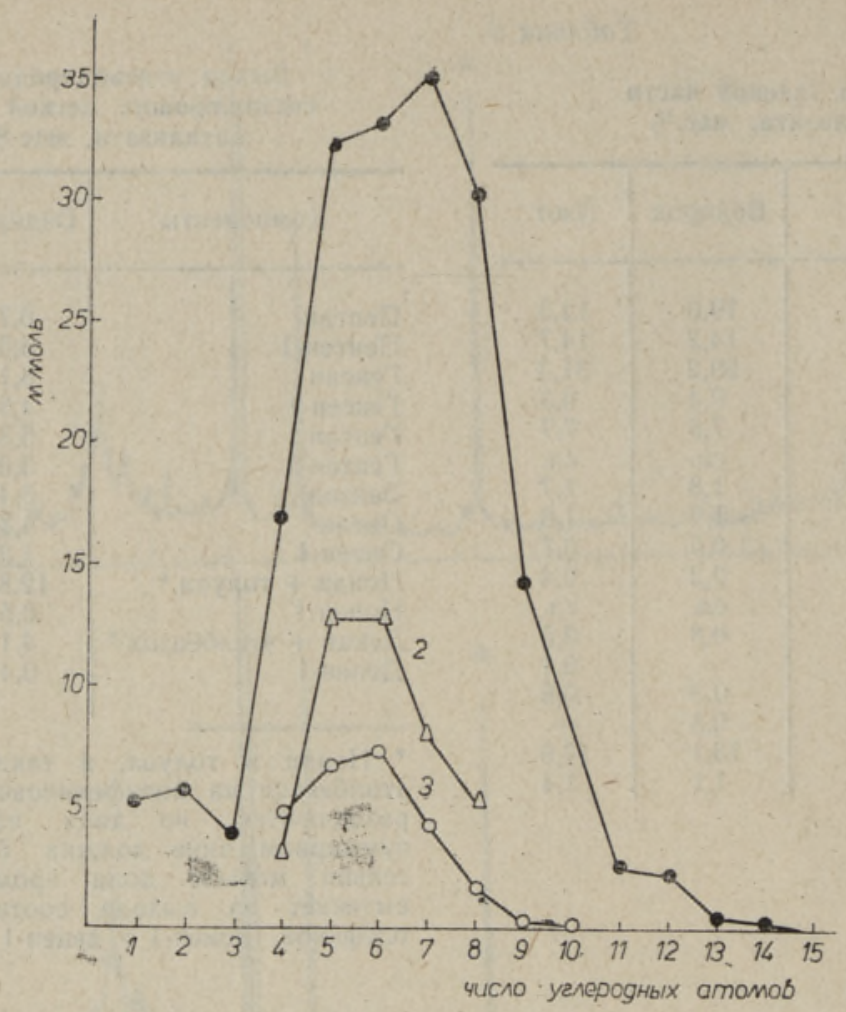

Рис. 3. Сравнение содержания 5-АР в исходном сырье и выхода парафинов и $\alpha$-олефинов в легкой части катализата. 1 - содержание 5-АР в исходном сырье, по числу углеродных атомов в боковой цепи; 2,3 - выход парафннов и $\alpha$-олефинов при деалкилировании 5 -АР, по числу углеродных атомов.

тате отрыва алкильного радикала от длинноцепочечного 5-АР (табл. 4). Выход отдельных парафинов и $\alpha$-олефинов в легкой части катализата коррелируется с содержанием представителей 5-AР, имеющих в боковой цепи на $1-2$ углеродные атома болыше (рис. 3), что, в свою очередь, говорит о разрыве алкильной цепи в $\beta$ - и $\gamma$-положениях. Иоключение составляют газообразные углеводороды $\mathrm{C}_{1}-\mathrm{C}_{3}$ (табл. 3) их количество в несколько десятков раз превышает количество 5-АР, которые также способствуют их появлению. Это объясняется дальнейшим разложением вторичных продуктов, а также разложением других фенольных структур в исходном сырье.

Полученные экспериментальные данные позволяют предположить образование водорастворимых 5-AР в результате следующих реакций:

или

$$
\begin{aligned}
\mathrm{Ph}(\mathrm{OH})_{2} \mathrm{CH}_{2} \mathrm{CH}_{2} \mathrm{CH}_{2} \mathrm{R} & \rightarrow \mathrm{Ph}(\mathrm{OH})_{2} \mathrm{CH}_{2} \cdot \cdot \mathrm{CH}_{2} \mathrm{CH}_{2} \mathrm{R} \\
\cdot \mathrm{CH}_{2} \mathrm{CH}_{2} \mathrm{R}+\mathrm{H}_{2} & \rightarrow \mathrm{CH}_{3} \mathrm{CH}_{2} \mathrm{R}+\mathrm{H} \cdot
\end{aligned}
$$

По нашему представлению, действие активного угля проявляется в том, что боковая цепь 5-АР адсорбируется на нем, а потом следует разрыв цепи, в основном в $\beta$ - или $\gamma$-положениях (1). Один из возникших радикалов на активном угле образует парафин или $\alpha$-олефин $(2)$, 
(3), а второй радикал присоеднняется к атому водорода, в результате чего образуется водорастворимый 5-АР (4).

Из $\left[{ }^{12,13}\right]$ известно, что параллельно с другими процессами разложения, алкилфенолы дегидроксилируются на активном угле, и поэтому имеется основание предполагать, что изученный нами фенольный материал также дегидроксилируется в вышеуказанных условиях. Доказательством этому служит наличие воды в составе катализата (табл.2). Присутствие бензола, толуола и этилбензола в легкой части катализата говорит также о том, что часть 5-АР действительно должна подчиняться гидрогенолитическому дегидроксилированию.

В числе продуктов разложения концентрата 5-АР присутствуют моноокись и двуокись углерода. В отсутствие кислорода СО может образовываться двумя путями: при разрыве ядра фенола или под действием водяного пара на уголь [14]. Первый путь мало вероятен из-за низкой температуры процесса, а второй,

$$
\mathrm{C}+\mathrm{H}_{2} \mathrm{O}=\mathrm{CO}+\mathrm{H}_{2}-Q \text {, }
$$

термодинамически вполне обоснован в наших условиях деалкилирования. Процесс образования $\mathrm{CO}_{2}$ может быть объяснен в основном экзотермической реакцией $\left[{ }^{14}\right]$ :

$$
\mathrm{CO}+\mathrm{H}_{2} \mathrm{O}=\mathrm{CO}_{2}+\mathrm{H}_{2}+Q \text {. }
$$

При деалкилировании концентрата 5-АР на активном угле наблюдается весьма быстрое падение каталитической активности угля. Как показывает наш опыт, это сопровождается значительным увеличением массы катализатора. Так как такой катализатор не освобождается от привеса при обработке его органическими сольвентами и подщелоченным органико-водным растворителем даже при повышенных температурах $\left(70-80^{\circ}\right)$, то можно сделать вывод об образовании коксоподобных продуктов на катализаторе, что и вызывает понижение его активности. Отметим также, что не удалось установить различия в строении свежего и обработанного углей по ИК-спектрам. Поэтому не можем сказать ничего определенного об изменении структуры угля в процессе деалкилирования.

\section{ЛИТЕРА Т У Р А}

1. Л асн И., Калде Л., Клесмен т И. О термокаталитическом превращении высших сланцевых 5-алкилрезорцинов на активных углях. - Изв. АН ЭССР. Хим., 1980 , т. 29 , № 1 , с. $12-17$.

2. Л аури М. Ю., Л ас н И. М. О применении симплексного метода планирования экспериментов для определения оптимальных условий и протекания технологического процесса. - Горючие сланцы, 1980, № 6, с. 13-17.

3. Л а сн И. М., К а лде Л. Я. Деалкилирование длинноцепных сланцевых 5-алкилрезорцинов на активном угле при пониженных давлениях. - Горючие сланцы, 1980 , № 6 , с. $18-21$.

4. Л асн И. М., Калде Л. Я. Уточнение условнй деалкилирования 5-алкилре́зорцинов на активном угле. - Горючие сланцы, 1980, № 11, с. 5-10.

5. Лилле Ю. Э., Кундель Х. А., Пурре Т. А., Биттер Л. А. О пиролизе алкнлрезорщинов. - Хим. тверд. топл., 1972 , № 3, с. $128-134$.

6. Milnes, M. H., De a n, R. E. The catalytic dealkylation of alkylphenols at atmospheric pressure. - J. Appl. Chem. Biotechnol., 1971, v. 21, p. 287-296.

7. Гоникберг М. Г., Ли Гу ан-Н янь. Исследование гомогенного деструктизного гидрирования пропилфенолов под давлением водорода. - Изв. АН CCCP, OXH, 1961, № 3, c. 491-495.

8. Р аудсепп Хели, Р а удсепп Х. Исследованне термической деструкции пропил- и бутилфенолов в присутствии водяного пара. - Изв. АН ЭССР. Хнм., Геол., 1971, т. 20, № 1, с. 3-7.

9. Sweeting, J. W., Wilshire, J. F. K. The pyrolysis of $\omega \omega^{\prime}$-diphenylalkanes. - Austral. J. Chem., 1962, v. 15, p. 89-103.

10. B a d ger, G.. M., S pots wood, T. M. The formation of aromatic hydrocar- 
bons at high temperatures. Part IX. The pyrolysis of toluene, ethylbenzene, propylbenzene and butylbenzene. - J. Chem. Soc., 1960, v. 11, p. 4420-4427.

11. В и й рес А. Х., Клесмент И. Р. Результаты опытов выделения алкилрезорцинов с длинной боковой цепью. - Горючие сланцы, 1976, № 5, с. 13-17.

12. Ш у й к и Н Н. И., В и к то ро в а 3. А. Контактно-каталитические превращения крезолов. - В кн.: Новые методы рационального использования местных топлив (тр. АН Латв. ССР). Рига, 1959, с. 265-276.

13. Milnes, M. H., Dea n, R. E. The catalytic dealkylation of alkylphenols at elevated pressures. - J. Appl. Chem. Biotechnol., 1972, v. 22, p. 1095-1115.

14. Вольфкович С. И., Е горов А. П., Эпштейн Д. М. Общая химическая технология, М.-Л., 1953 , т. 1, с. $250-251$.

Институт химии

Академии наук Эстонской ССР

НИиС

Институт сланцев
Поступнла в редакцию 19/VI 1981

\section{J. LASN, L. KALDE, I. KLESMENT, V. VASSILJEV}

\section{POLEVKIVI 5-ALKUOLRESORTSIINIDE DESALKUOLIMISEST}

Artiklis kirjeldatud katsetes desalküüliti alküülresortsiine, mille kõrvalahelas oli $4-10$ süsinikuaatomit. Katsed tehti aktiivsöel temperatuuril $572^{\circ} \mathrm{C}$ ja rõhul 13,3 kPA vesiniku, lämmastiku või veeauru voolus. Alküülresortsiine, mille kõrvalahelas oli kuni 4 süsinikuaatomit, moodustus $30 \%$ (sōltumata kandegaasist). Artiklis on esitatud desalküülimise mehhanism ning väidetud, et hüdrogeenimine ja hüdrogenolüüs kulgevad ka molekulaarse vesinikuta, koksi dehüdrogeenimisel ja vee konversioonil eralduva vesiniku arvel.

\section{LASN, L. KALDE, I. KLESMENT, V. VASILYEV}

\section{ON THE THERMOCATALYTIC DEALKYLATION OF SHALE OIL 5-ALKYL RESORCINOLS}

A mixture of 5-alkyl resorcinols having 4-10 carbon atoms in the side chain was subjected to dealkylation. The experiments were performed at $572{ }^{\circ} \mathrm{C}$ at $13.3 \mathrm{kPa}$ in a stream of hydrogen, nitrogen or steam, on charcoal. The yield of 5 -alkyl resorcinols with $0-4$ carbon atoms in the side chain was $30 \%$, independently of the carrier gas composition. The mechanism of the side chain splitting in the form of paraffin or olefin is presented as well as the role of hydrogenation and dehydroxylation processes indicated.

The processes of hydrogenation and hydrogenolysis proceed also in the absence of molecular hydrogen as a result of the coke dehydrogenation and water conversion. 